\title{
Measurement of Genetic Diversity of Chinese Seashore Paspalum Resources through Morphological and Sequence-related Amplified Polymorphism Analysis
}

\author{
Yan Liu, Hailin Guo, Yi Wang, Jingang Shi, and Dandan Li \\ Institute of Botany, Jiangsu Province and Chinese Academy of Sciences, Nanjing 210014, China \\ Zhiyong Wang \\ College of Agriculture, Hainan University, Haikou 570228, China \\ Jianxiu Liu \\ Institute of Botany, Jiangsu Province and Chinese Academy of Sciences, Nanjing 210014, China
}

ADDITIONAL INDEX wORDS. genetic variation, molecular markers, morphological characteristics, Paspalum vaginatum, SRAP

\begin{abstract}
Seashore paspalum (Paspalum vaginatum) is a notable warm-season turfgrass. Certain germplasm resources are distributed in the southern regions of China. The objectives of this study were to investigate the genetic diversity and genetic variation of Chinese seashore paspalum resources. Morphological characteristics and sequence-related amplified polymorphism (SRAP) markers were used to assess genetic relationships and genetic variation among 36 germplasm resources from China and six cultivars from the United States. The results showed significant variation for 13 morphological characteristics among 42 tested seashore paspalum accessions, and that the phenotypic $\mathrm{CV}$ was, in turn, turf height $>$ turf density $>$ internode length $>$ inflorescence density $>$ leaf width $>$ reproductive branch height $>$ spikelet width $>$ leaf length $>$ spikelet number $>$ inflorescence length $>$ internode diameter $>$ inflorescence width $>$ spikelet length. According to the morphological characteristics and cluster analysis, 42 seashore paspalum accessions were divided into six morphological types. In total, 374 clear bands were amplified using 30 SRAP primer combinations; among these bands, 321 were polymorphic with $85.83 \%$ polymorphism. SRAP marker cluster analysis showed that $\mathbf{4 2}$ seashore paspalum accessions were grouped into seven major groups, with a genetic similarity coefficient ranging from 0.4385 to 0.9893 and genetic distance values ranging from 0.0108 to 0.8244 . The high level of genetic diversity occurred among Chinese germplasm, and the genetic distance was relatively high between Chinese germplasm and cultivars introduced from the United States. The patterns in morphological trait variations and genetic diversity will be useful for the further exploitation and use of Chinese seashore paspalum resources.
\end{abstract}

Seashore paspalum is a notable warm-season turfgrass that survives in coastal areas between latitudes $30^{\circ} \mathrm{N}$ and $30^{\circ} \mathrm{S}$ worldwide (Liu et al., 1994). When the average temperature is less than 10 to $15.5^{\circ} \mathrm{C}$, this grass becomes dormant and loses its green color (Harivandi et al., 1984). Seashore paspalum was initially identified on public grounds, parks, golf courses, and athletic fields (Duncan, 1999). Because of high-quality turfgrass production and relatively low fertility inputs, this grass has considerable potential in the home lawn market (Trenholm and Unruh, 2002). Seashore paspalum can tolerate soil salinity levels as high as $54 \mathrm{dS} \cdot \mathrm{m}^{-1}$ (Brosnan and Deputy, 2008) and soil water $\mathrm{pH}$ ranging from 3.6 to 10.2 (Duncan, 1994). This grass can also tolerate low light, mowing heights of less than $1.3 \mathrm{~cm}$, and drought stress (Brosnan and Deputy, 2008; Huang et al., 1997; Jiang et al., 2004); and shows low-temperature tolerance similar to that of hybrid bermudagrass [Cynodon dactylon $\times$ Cynodon transvaalensis (Duncan and Carrow, 2000)]. Mor-

Received for publication 26 Mar. 2019. Accepted for publication 18 July 2019 This work was supported financially by the National Natural Science Foundation of China (31572155), the 333 Talents Project of Jiangsu Province of China, the Jiangsu Key Laboratory for the Research and Utilization of Plant Resources (QD201301), and the Jiangsu Provincial Public Institutions Program for Research Conditions and Building Capacity (BM2015019).

H.G. is the corresponding author. E-mail: ghlnmg@sina.com. phologically, seashore paspalum is similar to bermudagrass (Cynodon sp.), with strong stolons and rhizomes.

Seashore paspalum is widely grown in China. Several cultivars, including Adalayd, Salam, Seaspray, and Sea Isle2000 introduced from America are broadly used in China. However, these cultivars cannot grow well because of poor adaptation to local environments in China. There are a number of seashore paspalum germplasm resources distributed in southern China. However, there is limited information on the characterization of these germplasm resources. Xie (2004) collected three natural populations from Guangzhou in China and analyzed their genetic diversity by random amplified polymorphic DNA (RAPD) marker technology. The results of this study showed high genetic variation among populations. Luo et al. (2013) studied the turf quality of seashore paspalum Line 09-1, which is bred from natural populations in southern China, and the results showed this grass had outstanding turf quality and potential for further popularization and application. We collected 36 germplasm resources of seashore paspalum from Guangdong and Hainan in China in 2003. These resources grow naturally in seaside, natural grassland, roadside, or farmland areas, and cover the main natural distribution areas of seashore paspalum in China. Thus, it is important to analyze the genetic diversity of 
these seashore paspalum resources for further exploitation and use.

Morphological analysis is a useful tool to study trait variation and characterize germplasm resources. This tool has been used to assess the variability of natural populations of Paspalum dilatatum, and the results showed the phenotypic variance within populations contained, on average, $26 \%$ of genetic variance (García et al., 2002). High morphological variability is desirable for germplasm conservation and selection of parents in breeding programs (Khadivi-Khub et al., 2014). However, environmental factors and genetic composition can both influence variance in morphological analysis.

Molecular techniques have been applied to assess the genetic variance and genetic relationships of certain crops (Chakravarthi and Naravaneni, 2006; Liu et al., 1995; Wang et al., 2011). Several molecular markers, such as restriction fragment length polymorphism markers, simple sequence repeat markers, amplified fragment length polymorphism markers, and RAPD markers have been used to research the genetic diversity of the genus Paspalum (Jarret et al., 1998; Liu et al., 1995; Xie, 2004). Compared with morphological analysis, the genetic variance at the molecular level is not influenced by environmental factors. SRAP markers have the advantages of simplicity and reliability, and the potential for disclosing numerous codominant markers ( $\mathrm{Li}$ and Quiros, 2001). SRAP markers have been adapted as a tool to study the genetic diversity of different plants, such as pea (Pisum sativum), arabica coffee (Coffea arabica), qingke (Hordeum vulgare var. nudum), pumpkin (Cucurbita pepo), and white chitarak (Plumbago zeylanica) (Espósito et al., 2007; Ferriol et al., 2003; Haji et al., 2014; Mishra et al., 2011; Yang et al., 2010).

In the present study, morphological characteristics and SRAP markers were used to analyze the genetic diversity and relationships among $42 P$. vaginatum resources. The variability of certain morphological characteristics and SRAP markers among seashore paspalum resources was also revealed. The results will be useful for the exploitation, use, and breeding of seashore paspalum resources in China.

\section{Materials and Methods}

Plant materials. Six cultivars introduced from America and 36 seashore paspalum germplasm collected from China at various locations, as indicated in Table 1, were used in this study. Each accession was planted using stolons in a $1-\mathrm{m}^{2}$ plot in an experimental field at the Institute of Botany, Jiangsu Province and Chinese Academy of Sciences (lat. $31^{\circ} 51^{\prime} \mathrm{N}$, long. $118^{\circ} 59^{\prime} \mathrm{E}$; elevation, $6 \mathrm{~m}$ ) in 2013 . All the stolons of each accession come from one plant, and plants for each accession used for the experiment were propagated clonally. Each accession was planted in 10 rows of equidistant plants in a single, unreplicated plot. The plots were spaced $0.5 \mathrm{~m}$ apart and were maintained by timely trimming to prevent contamination between the accessions. Irrigating, fertilizing, and applying fungicide were conducted as required to maintain turf health. After $70 \%$ of the plot was covered by turf, the plots were mowed frequently at a height of 0.03 to $0.04 \mathrm{~m}$ to ensure the turf remained healthy and developed newly expanded leaf blades. After green-up in Spring 2015, we ceased mowing so that the grass could grow naturally, and different morphological and reproductive traits could be observed to evaluate genetic diversity.

Morphological ChaRACTERISTIC DATA COLlection. Morphological characterization was conducted from June to Aug. 2015. Variation and diversity of morphological characteristics were evaluated by measuring six vegetative and seven reproductive traits. Among the characteristics evaluated, turf

Table 1. Accessions and collection sites in China (including latitude, longitude, and altitude) of 42 Paspalum vaginatum included in this study of genetic diversity.

\begin{tabular}{|c|c|c|c|c|c|c|c|c|c|}
\hline Accession & Collection site & Latitude & Longitude & Altitude (m) & Accession & Collection site & Latitude & Longitude & Altitude (m) \\
\hline P02 & Zhuhai, Guangdong & $22^{\circ} 09^{\prime} \mathrm{N}$ & $113^{\circ} 32^{\prime} \mathrm{E}$ & 5 & $\mathrm{P} 45$ & Lingshui, Hainan & $18^{\circ} 26^{\prime} \mathrm{N}$ & $109^{\circ} 59^{\prime} \mathrm{E}$ & 6 \\
\hline P05 & Zhuwanding, Aomen & $22^{\circ} 06^{\prime} \mathrm{N}$ & $113^{\circ} 32^{\prime} \mathrm{E}$ & 4 & P46 & Lingshui, Hainan & $18^{\circ} 25^{\prime} \mathrm{N}$ & $109^{\circ} 57^{\prime} \mathrm{E}$ & 4 \\
\hline P06 & Zhuhai, Guangdong & $22^{\circ} 05^{\prime} \mathrm{N}$ & $113^{\circ} 31^{\prime} \mathrm{E}$ & 5 & P47 & Lingshui, Hainan & $18^{\circ} 25^{\prime} \mathrm{N}$ & $109^{\circ} 57^{\prime} \mathrm{E}$ & 4 \\
\hline P13 & Zhuhai, Guangdong & $22^{\circ} 05^{\prime} \mathrm{N}$ & $113^{\circ} 31^{\prime} \mathrm{E}$ & 4 & P49 & Sanya, Hainan & $18^{\circ} 18^{\prime} \mathrm{N}$ & $109^{\circ} 19^{\prime} \mathrm{E}$ & 5 \\
\hline P14 & Zhuhai, Guangdong & $22^{\circ} 05^{\prime} \mathrm{N}$ & $113^{\circ} 31^{\prime} \mathrm{E}$ & 4 & P50 & Sanya, Hainan & $18^{\circ} 18^{\prime} \mathrm{N}$ & $109^{\circ} 19^{\prime} \mathrm{E}$ & 5 \\
\hline P17 & Danzhou, Hainan & $19^{\circ} 44^{\prime} \mathrm{N}$ & $109^{\circ} 12^{\prime} \mathrm{E}$ & 4 & P52 & Sanya, Hainan & $18^{\circ} 19^{\prime} \mathrm{N}$ & $109^{\circ} 12^{\prime} \mathrm{E}$ & 5 \\
\hline P27 & Lingaojiao, Hainan & $19^{\circ} 56^{\prime} \mathrm{N}$ & $109^{\circ} 41^{\prime} \mathrm{E}$ & 5 & P54 & Ledong, Hainan & $18^{\circ} 27^{\prime} \mathrm{N}$ & $108^{\circ} 57^{\prime} \mathrm{E}$ & 4 \\
\hline P28 & Lingaojiao, Hainan & $19^{\circ} 56^{\prime} \mathrm{N}$ & $109^{\circ} 41^{\prime} \mathrm{E}$ & 5 & P55 & Dongfang, Hainan & $19^{\circ} 06^{\prime} \mathrm{N}$ & $109^{\circ} 43^{\prime} \mathrm{E}$ & 4 \\
\hline P29 & Lingaojiao, Hainan & $19^{\circ} 56^{\prime} \mathrm{N}$ & $109^{\circ} 41^{\prime} \mathrm{E}$ & 5 & P56 & Dongfang, Hainan & $19^{\circ} 06^{\prime} \mathrm{N}$ & $109^{\circ} 43^{\prime} \mathrm{E}$ & 4 \\
\hline P30 & Lingaojiao, Hainan & $19^{\circ} 56^{\prime} \mathrm{N}$ & $109^{\circ} 41^{\prime} \mathrm{E}$ & 5 & P58 & Haikou, Hainan & $20^{\circ} 03^{\prime} \mathrm{N}$ & $110^{\circ} 18^{\prime} \mathrm{E}$ & 5 \\
\hline P32 & Chengmai, Hainan & $19^{\circ} 57^{\prime} \mathrm{N}$ & $109^{\circ} 53^{\prime} \mathrm{E}$ & 4 & P60 & Haikou, Hainan & $20^{\circ} 03^{\prime} \mathrm{N}$ & $110^{\circ} 18^{\prime} \mathrm{E}$ & 6 \\
\hline P33 & Chengmai, Hainan & $19^{\circ} 57^{\prime} \mathrm{N}$ & $109^{\circ} 53^{\prime} \mathrm{E}$ & 4 & P64 & Sanya, Hainan & $32^{\circ} 59^{\prime} \mathrm{N}$ & $117^{\circ} 14^{\prime} \mathrm{E}$ & 6 \\
\hline P41 & Wanning, Hainan & $19^{\circ} 02^{\prime} \mathrm{N}$ & $110^{\circ} 31^{\prime} \mathrm{E}$ & 4 & Sea Isle 2000 & \multicolumn{4}{|c|}{ Introduced from the United States } \\
\hline P42 & Wanning, Hainan & $13^{\circ} 59^{\prime} \mathrm{N}$ & $110^{\circ} 29^{\prime} \mathrm{E}$ & 4 & Seadwarf & \multicolumn{4}{|c|}{ Introduced from the United States } \\
\hline P44 & Lingshui, Hainan & $18^{\circ} 26^{\prime} \mathrm{N}$ & $109^{\circ} 59^{\prime} \mathrm{E}$ & 6 & Seaspray & \multicolumn{4}{|c|}{ Introduced from the United States } \\
\hline
\end{tabular}


density, turf height, inflorescence density, and reproductive branch length were analyzed in the plots in the experiment field; the other measurements were obtained after transferring the material from the field to the laboratory. Turf density and inflorescence density indicate the number of shoots and inflorescences, respectively, present in a $0.1 \times 0.1-\mathrm{m}$ wire frame. Both turf density and inflorescence density were measured during five random samplings of their experimental field plots. Spikelet number indicates the number of spikelets for each inflorescence. Turf height, leaf length, internode length, reproductive branch height, and inflorescence length were measured with a ruler. Leaf width, internode diameter, inflorescence width, and spikelet length and width were measured using Vernier calipers. With the exception of turf density and inflorescence density, each plant trait was evaluated during 10 random samplings of each plot. Statistical software (SPSS version 19.0; IBM Corp., Armonk, NY) and spreadsheet software (Excel version 2000; Microsoft Corp., Redmond, WA) were used to analyze the variation and diversity of morphological characteristics.

DNA EXTRACTION, POLYMERASE CHAIN REACTION (PCR) AMPLIFICATION, AND ELECTROPHORESIS. Genomic DNA was extracted from 8 to 10 fresh leaves selected randomly in the plot of each accession by using a plant genomic DNA extraction kit (Yuanpinghao Biotech Co., Tianjin, China). The quality of the extracted DNA was verified by $1 \%$ agarose gel electrophoresis. The DNA samples were stored at $-20{ }^{\circ} \mathrm{C}$. The DNA samples $(50 \mathrm{ng})$ were amplified in $10-\mu \mathrm{L}$ reaction volumes containing $1 \mu \mathrm{L}$ of $10 \times$ PCR buffer, $2.50 \mathrm{mmol} \cdot \mathrm{L}^{-1} \mathrm{Mg}^{2+}, 150$ $\mu \mathrm{mol} \cdot \mathrm{L}^{-1}$ deoxyribonucleotide triphosphate, $0.4 \mu \mathrm{mol} \cdot \mathrm{L}^{-1}$ primer, and 1.5 U Taq DNA polymerase. Thirty primer combinations were selected for consistent banding patterns and high polymorphism using conditions of previously optimized SRAP-PCR System (Liu et al., 2016). The primer sequences are shown in Table 2. The mixtures were overlaid with one drop of heavy mineral oil. The PCR was conducted in a generic description (MyCycler; Bio-Rad, Shanghai, China) with the following program: denaturation at $94{ }^{\circ} \mathrm{C}$ for $4 \mathrm{~min}$ followed by five cycles of denaturation at $94{ }^{\circ} \mathrm{C}$ for $1 \mathrm{~min}$, annealing at $37^{\circ} \mathrm{C}$ for $1 \mathrm{~min}$, and extension at $72{ }^{\circ} \mathrm{C}$ for $1 \mathrm{~min}$; 35 cycles of denaturation at $94{ }^{\circ} \mathrm{C}$ for $1 \mathrm{~min}$, annealing at $50{ }^{\circ} \mathrm{C}$ for $1 \mathrm{~min}$, and extension at $72{ }^{\circ} \mathrm{C}$ for $1 \mathrm{~min}$; followed by a final extension at $72{ }^{\circ} \mathrm{C}$ for $7 \mathrm{~min}$. The PCR products were mixed with $6 \times$ loading buffer before sample loading. Electrophoresis was run at $270 \mathrm{~V}$ for $\approx 90 \mathrm{~min}$. The DNA bands were separated on $10 \%$ polyacrylamide nondenaturing gels and were detected

Table 2. Forward and reverse sequence-related amplified polymorphism primer information for the genetic diversity analysis of Paspalum vaginatum in this study.

\begin{tabular}{|c|c|c|c|}
\hline Code & Forward primers & Code & Reverse primers \\
\hline$\overline{\mathrm{Me} 1}$ & 5'-TGAGTCCAAACCGGATA-3' $^{\prime}$ & Em1 & $\overline{5^{\prime} \text {-GACTGCGTACGAATTCAA-3' }}$ \\
\hline $\mathrm{Me} 2$ & 5'-TGAGTCCAAACCGGAGC-3' & Em2 & 5'-GACTGCGTACGAATTCTG-3' \\
\hline Me3 & $5^{\prime}$-TGAGTCCAAACCGGACC-3' & Em3 & 5'-GACTGCGTACGAATTGAC-3' \\
\hline Me4 & 5'-TGAGTCCAAACCGGACA-3' & Em4 & 5'-GACTGCGTACGAATTTGA-3' \\
\hline Me5 & 5'-TGAGTCCAAACCGGTGC-3' & Em5 & 5'-GACTGCGTACGAATTAAC-3' \\
\hline Me6 & 5'-TGAGTCCAAACCGGAGA-3' & Em6 & 5'-GACTGCGTACGAATTGCA-3' \\
\hline Me7 & 5'-TGAGTCCAAACCGGACG-3' & Em7 & 5'-GACTGCGTACGAATTGAG-3' \\
\hline Me8 & 5'-TGAGTCCAAACCGGAAA-3' & Em8 & $5^{\prime}$-GACTGCGTACGAATTGCC-3' \\
\hline Me9 & 5'-TGAGTCCAAACCGGAAC-3' & Em9 & 5'-GACTGCGTACGAATTTCA-3' \\
\hline Me10 & 5'-TGAGTCCAAACCGGAAT-3' & Em10 & 5'-GACTGCGTACGAATTCAT-3' \\
\hline
\end{tabular}

using silver staining. Last, the bands were visualized using a gel documentation system. The clear DNA bands were scored as 1 (present) or 0 (absent), and Nei's genetic identity and genetic distance were computed by using POPGENE software 3.2 (Yeh et al., 1997). Dendrograms were constructed with MEGA 3.1 software (Kumar et al., 2004).

\section{Results}

PhenotyPic VARIATION OF MORPHOLOGICAL CHARACTERISTICS AMONG Different ACCESSIONS. Significant variation for 13 morphological characteristics was observed among the 42 tested seashore paspalum accessions (Supplemental Table 1). Among these characteristics, maximum phenotypic variation values of $30.96 \%$ and $29.93 \%$ were observed for turf height and density, respectively. The minimum $\mathrm{CV}$ was observed for the spikelet length and inflorescence width, which were $7.58 \%$ and $11.11 \%$, respectively (Table 3 ). The morphological cvwas, in turn, turf height $>$ turf density $>$ internode length $>$ inflorescence density $>$ leaf width $>$ reproductive branch height $>$ spikelet width $>$ leaf length $>$ spikelet number $>$ inflorescence length $>$ internode diameter $>$ inflorescence width $>$ spikelet length. The coefficients of phenotypic variation for all 12 characteristics were greater than $10 \%$, and significant morphological differences were observed among different accessions. In the present study, the coefficients of variation for density, turf height, leaf width, internode length, inflorescence density, and reproductive branch height were greater than $20 \%$. The $\mathrm{CV}$ within other morphological indices were between $10 \%$ and $20 \%$. Only the CV for spikelet length was less than $10 \%$. The results showed rich morphological variation among the 42 seashore paspalum germplasm resources.

Morphological CHARACTERISTIC Cluster anAlysis. The Euclidean distance averaging method was used to analyze the 42 seashore paspalum resources based on the observed results of 13 morphological characteristics. Morphological data were processed with SPSS software (version 19.0). Based on a Euclidean distance of 15 , all $P$. vaginatum accessions were grouped into two main groups (Fig. 1). Group 1 was comprised of P33, P38, 'Adalayd', P40, and P46. This group has a greater turf density than the other groups, slightly more slender leaves, smaller internode diameters, and greater inflorescence density than the other groups. Thus, this group was referred to as a fineleaf texture and high-density ecotype. Based on a Euclidean distance of 10 , group 2 was further divided into three subgroups: A, B, and C. Subgroup A contained P44, P58, P47, P39, $\mathrm{P} 54$, and P53. In this group, the leaves were relatively wide, and the turf density and inflorescence density were less than that of other groups. The inflorescence lengths were longer and these grasses produced more seeds per panicle than the other groups. Therefore, this group was referred to as the wideleaf texture and low-density ecotype. 'Seadwarf', 'SeaIsle2000', 'Seaspray', 'Salam', 'Platinum TE', and P55 were included in subgroup B. In subgroup B, the turf height was relatively low, the leaves were short and thin, the density was 
Table 3. Morphological variation of 42 Paspalum vaginatum accessions analyzed in this study with mean value, maximum value, minimum value, $\mathrm{SD}$, and $\mathrm{CV}$ for each morphological character.

\begin{tabular}{lrrrrr}
\hline Statistical parameters & Mean & Minimum & Maximum & \multicolumn{1}{c}{ SD } & CV (\%) \\
\hline Turf density $\left(\right.$ no. $\left./ 100 \mathrm{~cm}^{2}\right)$ & 86.46 & 37.00 & 159.67 & 26.75 & 30.94 \\
Turf ht $(\mathrm{cm})$ & 20.32 & 7.30 & 32.10 & 6.29 & 30.96 \\
Leaf length (cm) & 8.43 & 5.51 & 10.99 & 15.34 & 18.19 \\
Leaf width (mm) & 5.03 & 2.68 & 7.34 & 1.18 & 23.51 \\
Internode length (cm) & 4.48 & 1.51 & 6.66 & 1.33 & 29.58 \\
Internode diam (mm) & 2.13 & 1.58 & 2.82 & 0.31 & 14.44 \\
Inflorescence density (no./100 $\mathrm{cm}^{2}$ ) & 52.15 & 23.33 & 96.67 & 14.02 & 26.88 \\
Reproductive branch ht (cm) & 38.21 & 19.84 & 52.75 & 7.67 & 20.07 \\
Inflorescence length (cm) & 4.08 & 2.46 & 4.93 & 0.60 & 14.76 \\
Inflorescence width (mm) & 1.56 & 1.20 & 1.89 & 0.17 & 11.11 \\
Spikelet length (mm) & 2.84 & 2.34 & 3.28 & 0.22 & 7.58 \\
Spikelet width (mm) & 13.92 & 7.06 & 19.38 & 2.72 & 19.53 \\
Spikelet (no.) & 28.85 & 16.80 & 39.00 & 5.16 & 17.89 \\
\hline z & & & & &
\end{tabular}

${ }^{\mathrm{z}}$ Number of spikelets for each inflorescence.

greater than that in subgroup $\mathrm{A}$, the reproductive branch height and inflorescence length were shorter than those in the other groups, the spikelet width was narrow, and fewer seeds per panicle were observed compared with other groups; thus, this group was named the dwarf high-density ecotype. Based on a Euclidean distance of 5, subgroup $\mathrm{C}$ was divided into three small groups. Small group a, containing P29 and P42, was referred to as the high inflorescence density ecotype. The grasses had a high density of inflorescence, producing many seeds per panicle, with large spikelets. Small group b included 14 accessions and belonged to an intermediate ecotype between a and $\mathrm{c}$. Nine of the germplasm accessions that were included in small group c were more dense and taller than the other members in subgroup C. Most grasses in group c had long and thick internodes, except for P17 and P27. Thus, this small group was referred to as the thick and high-density ecotype. By cluster analysis, the 42 seashore paspalum accessions were divided into six morphological ecotypes. This information will provide valuable information for the further exploitation and use of $P$. vaginatum germplasm resources.

SRAP POLYMORPHISMS. From a total of 100 primer pairs screened using SRAP-PCR conditions optimized previously (Liu et al., 2016), 30 primer pairs displaying high polymorphism were selected. A total of 374 bands were generated by 30 primer combinations, and 321 of these bands showed rich polymorphism (85.83\%) (Table 4). Among the 30 primer combinations, four combinations displayed $100 \%$ polymorphism. The number of bands generated ranged from 6 to 18 , with a mean of 12.5 bands per primer. Primers Me1Em10 and Me5Em5 generated the greatest number of bands (18 bands). The amplified fragments ranged in size from 50 to $1500 \mathrm{bp}$.

GENETIC DIVERSITY AND CLUSTER ANALYSIS ON THE BASIS OF SRAP MARKERS. Three hundred twenty-one polymorphic bands were analyzed for genetic diversity, and the results showed that Nei's gene diversity ranged from 0 to 0.4997 and Shannon's information index ranged from 0 to 0.6929 . The average values were 0.4142 and 0.5992 , respectively. This finding indicated extensive SRAP variation among the germplasm resources of $P$. vaginatum. Within the 42 germplasm resources, the genetic similarity coefficient ranged from 0.4385 to 0.9893 , and the genetic distance values ranged from 0.0108 to 0.8244 (Supplemental Table 2). The average genetic similarity coefficient and genetic distance value were 0.5759 and 0.5678 , respectively. The genetic similarity coefficient between P64 and P60 from Haikou and Sanya of Hainan Province, respectively, was 0.9893. The smallest genetic similarity coefficient was found between P52 and P55, which were from Sanya and Dongfang of Hainan Province. A wide range of genetic similarity coefficients (0.4385-0.9893) was detected in the Chinese germplasm resources, suggesting a high level of genetic diversity among Chinese germplasm. The genetic similarity coefficient was relatively high among six U.S. cultivars, ranging from 0.7781 to 0.9171 , with an average value of 0.8463 . The genetic similarity coefficients between U.S. cultivars and Chinese germplasm were 0.4840 through 0.8155 , with an average value of 0.5465 . Cluster analysis by a dendrogram based on unweighted pair group method arithmetic mean (UPGMA) showed that 42 seashore paspalum resources were grouped into seven major groups (Fig. 2). Group I included all the U.S. cultivars. P60, P64, and P68, which were collected in Haikou, Sanya, and Danzhou, respectively, were clustered in group II. Group III contained P18-2, P27, P28, P29, P30, and P32, which were collected from Lingaojiao (P27, P28, P29, P30), Danzhou (P18-2), and Chengmai (P32). Group IV was the largest group, containing 13 accessions that were separated into three subgroups. The first subgroup contained P45, P46, P47, and P48, which were all collected from the Lingshui area. P38, which was collected from the Qionghai area, and $\mathrm{P} 40, \mathrm{P} 41$, and $\mathrm{P} 42$, which were collected from Wanning, formed the second subgroup. The third subgroup contained P33, P37, P39, P44, and P49, which were collected from different regions. In group V, seven accessions (P52, P53, P54, P55, P56, P58, and P50) were included. P52 and P50 were collected from Sanya, and P53 and P54 were collected from Ledong. These grasses have similar morphological characteristics. There were three materials (P13, P14, and P17) in group VI and four materials (P02, P06, P05, and P09) in group VII. P13 and P14 were collected from Guangdong, and P17 was collected from HaiNan. P02, P06, and P09 were collected from Guangdong, and P05 was collected from Aomen. These grasses originated from two provinces in China. Most of the accessions from the same regions were clustered together. However, certain materials did not cluster with accessions from the same region. A significant genetic difference was found among Chinese resources and U.S. cultivars.

COMPARISON OF THE DENDROGRAM DERIVED FROM MORPHOLOGICAL CHARACTERISTICS AND SRAP MARKERS. The dendrograms generated from morphological characteristics and molecular markers are inconsistent for different accessions. Molecular marker analysis indicated that six U.S. cultivars clustered together, but analysis based on the morphological characteristics showed that five U.S. cultivars clustered together, but the cultivar of Adalayd clustered with P33, P38, P40, and P46, which showed high turf density, slender leaves, long internodes and spikelets, and high inflorescence density, and were classified as fine-leaf textured and high-density 


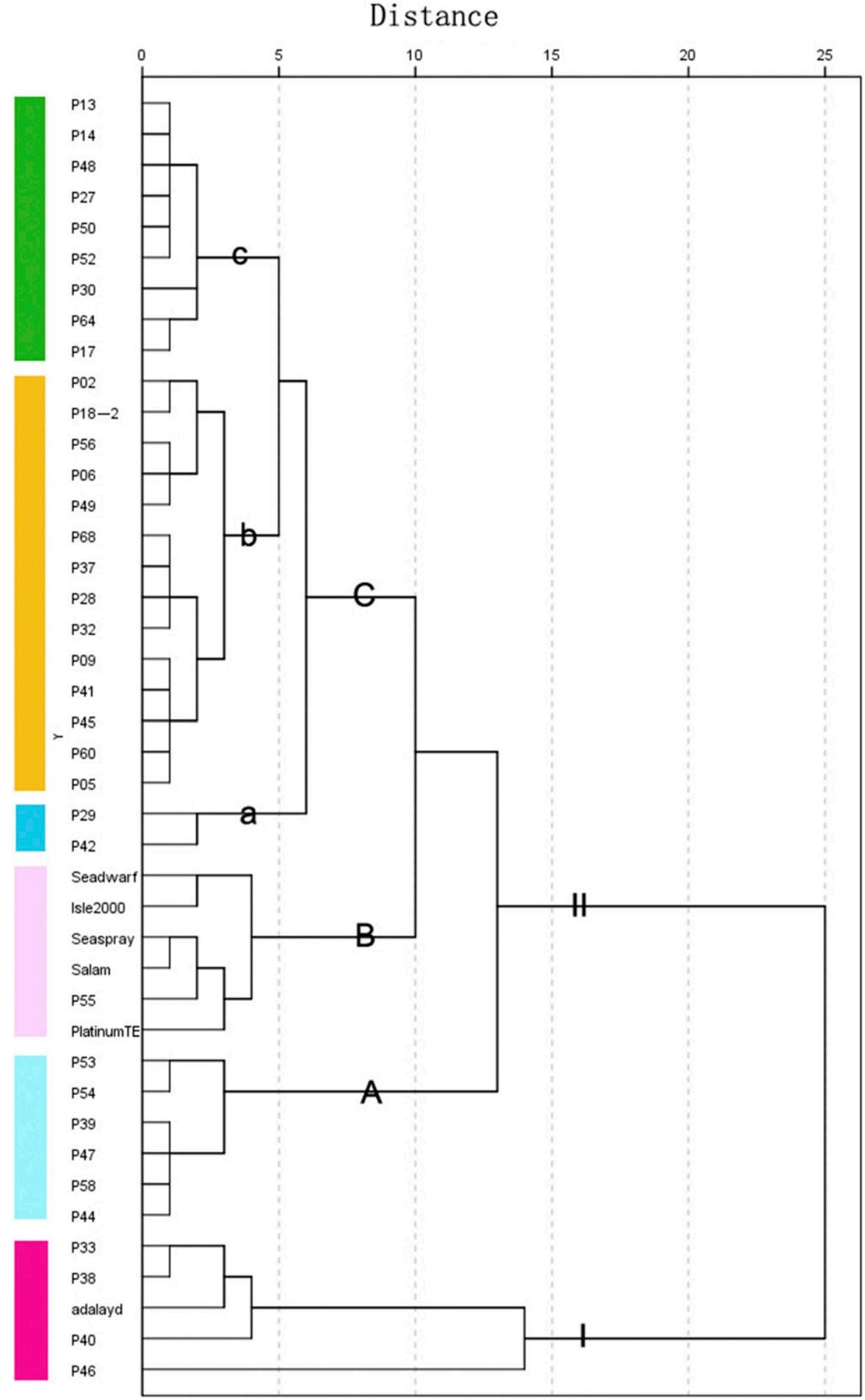

Fig. 1. An unweighted pair group method arithmetic mean dendrogram generated for 42 Paspalum vaginatum based on morphological characteristics. The scale bar represents rescaled Euclidean morphological distance. The color bars indicate the different morphological types as follows (top to bottom): thick and high-density ecotype (green), intermediate ecotype (yellow), high-inflorescence-density ecotype (blue), dwarf high-density ecotype (light pink), wide-leaf texture and low-density ecotype (light blue), and fine-leaf texture and highdensity ecotype (dark pink). ecotypes. P13 and P14, P02 and P06, P05 and P09, P53 and P54 were clustered together based on both morphological characteristics and SRAP markers. These cultivars were collected from the same region, except for P05 and P09. However, both P05 and P09 were from similar ecological environments. P05 was collected on the beach of Zuwanding in Aomen City and P09 was collected on the beach of Shilanzhou in Zhuhai City. The dendrogram based on SRAP markers showed that P45, P46, P47, and P48 (all from the same region: Lingshui County) clustered together; however, these cultivars clustered in different groups based on morphological traits. The abundant morphological variation was observed among these four accessions. This difference may result from the influence of the environment. Another group-P02, P18-2, P29, and P42-clustered together based on morphological traits, but these cultivars showed a large genetic distance based on molecular marker analysis. P02 was collected from beaches in Guangdong Province; P18-2 was collected from ancient salt fields in Hainan Province. Both these cultivars have a wide tolerance for environmental conditions. P29 and P42 were collected from Lingaojiao County of Hainan and Wanning's grassland, located northwest and southeast of Hainan.

\section{Discussion}

Morphological traits have been used to assess the phenotypic variability and phylogenetic relationships of various species (Chang et al., 2011; García et al., 2007; Jewell et al., 2012). In the present study, significant variation was found among the accessions of $P$. vaginatum for most morphological characteristics. The maximum variation value of turf height was $30.96 \%$. This turf height variation was less than the value obtained for C. dactylon (57.02\%) (Zheng et al., 2015). The turf height of Chinese germplasm accessions was greater than that for the six U.S. cultivars, except P55. The spikelet length had the minimum $\mathrm{CV}$ of $7.58 \%$. Leaf length and leaf width in six U.S. 
Table 4. Polymorphism results from amplification by 30 polymorphism primer combinations in 42 Paspalum vaginatum accessions in this study.

\begin{tabular}{|c|c|c|c|}
\hline Primer combinations & Bands (no.) & Polymorphic bands (no.) & Polymorphism rate $(\%)$ \\
\hline Me1Em1 & 11 & 9 & 81.82 \\
\hline Me1Em5 & 10 & 9 & 90.00 \\
\hline $\operatorname{Me} 1 \operatorname{Em} 7$ & 9 & 7 & 77.78 \\
\hline Me1Em8 & 10 & 9 & 90.00 \\
\hline Me1Em10 & 18 & 14 & 77.78 \\
\hline Me2Em1 & 8 & 6 & 75.00 \\
\hline $\mathrm{Me} 2 \mathrm{Em} 3$ & 16 & 10 & 62.50 \\
\hline Me2Em5 & 15 & 11 & 73.33 \\
\hline $\operatorname{Me} 3 \operatorname{Em} 7$ & 10 & 9 & 90.00 \\
\hline Me3Em8 & 15 & 13 & 86.67 \\
\hline $\mathrm{Me} 4 \mathrm{Em} 2$ & 11 & 9 & 81.82 \\
\hline Me4Em4 & 17 & 16 & 94.12 \\
\hline Me4Em5 & 13 & 10 & 76.92 \\
\hline Me4Em7 & 11 & 10 & 90.91 \\
\hline Me5Em5 & 18 & 17 & 94.44 \\
\hline Me6Em5 & 14 & 13 & 92.86 \\
\hline Me6Em6 & 15 & 15 & 100.00 \\
\hline Me6Em9 & 12 & 10 & 83.33 \\
\hline Me6Em10 & 16 & 13 & 81.25 \\
\hline Me7Em1 & 11 & 10 & 90.91 \\
\hline $\mathrm{Me} 7 \mathrm{Em} 2$ & 11 & 11 & 100.00 \\
\hline Me7Em4 & 11 & 10 & 90.91 \\
\hline Me7Em5 & 12 & 8 & 66.67 \\
\hline Me7Em7 & 12 & 10 & 83.33 \\
\hline Me8Em4 & 14 & 13 & 92.86 \\
\hline Me8Em5 & 14 & 13 & 92.86 \\
\hline Me8Em7 & 10 & 7 & 70.00 \\
\hline Me8Em8 & 6 & 5 & 83.33 \\
\hline Me8Em9 & 14 & 14 & 100.00 \\
\hline Me9Em4 & 10 & 10 & 100.00 \\
\hline Total & 374 & 321 & 85.83 \\
\hline
\end{tabular}

suggest that there is some polyploidy for Chinese accessions. Accurate ploidy levels will be determined by root tip chromosome counts in future experiments.

Through clustering analysis, 42 seashore paspalum germplasm resources and cultivars were divided into six different groups based on morphological traits. Germplasm collected from different regions were clustered together because they have similar characteristics. For example, P29 and P42 were clustered together because of the high inflorescence density, and these cultivars were collected from Lingaojiao and Wanning, which are located in the northwest and southeast regions, respectively, of Hainan Province. Certain Chinese germplasm resources and U.S. cultivars, such as P33, P38, P40, P46, and Adalayd, were also clustered together because of the similar fineleaf texture and high-density traits. Cluster analysis based on morphological traits showed that all groups had one or more characteristics that distinguish them from the other groups. We named each group based on their average traits to provide a good foundation for the further development and use of these germplasm resources. For example, group I was named the fine-leaf textured and high-density cultivars and P55 were shorter and thinner than those for the other Chinese germplasm resources. P55 and the six U.S. cultivars were similar based on morphological traits.

García et al. (2007) compared the vegetative and reproductive traits for the pentaploid and tetraploid biotypes of $P$. dilatatum. Their results showed that the pentaploid biotype had significantly greater values for most vegetative and reproductive characteristics than the tetraploid individuals. Espinoza and Quarín (1997) reported that diploids provide the genetic variability during the evolution of apomictic tetraploid Paspalum species. Paspalum vaginatum has typically been reported as diploid, and the chromosome number is $2 n=2 x=20$ (Duncan and Carrow, 2000; Echarte and Clausen, 1993). However, certain $P$. vaginatum accessions are polyploid (Eudy et al., 2017; Hojsgaard et al., 2009). In the present study, most Chinese seashore paspalum resources had larger organs than those of the U.S. cultivars. To determine whether the Chinese accessions in the present study are polyploid, the ploidy of all materials was tested by flow cytometry. The results showed that the DNA content of six U.S. cultivars was between 90.07 and 101.24, whereas the DNA content of Chinese accessions formed a continuous distribution, ranging from 91.78 to 258.37 and (H.L. Guo, unpublished data). We were unable to determine the accurate ploidy for each accession because of the continuous distribution characteristic; however, the results ecotype. Subgroup B was named the dwarf plants with highdensity ecotype. The phenotype of group 1 and subgroup B was a low grass layer, short and thin leaves, and high density. Both groups provide excellent germplasm for breeding new cultivars of seashore paspalum turfgrass. These groups included the six U.S. cultivars (Seadwarf, SeaIsle2000, Seaspray, Salam, Platinum TE, and Adalayd) and five wild germplasm resources (P33, P38, P40, P46, and P55). Small group c was referred to as the thick grass layer and high-density ecotype, which can provide excellent germplasm resources for water and soil conservation. Small group c contained accessions P13, P14, P17, P27, P30, P48, P50, P52, and P64.

The SRAP marker is a reliable marker that has been widely used in different studies. This type of marker provides valuable information on the genetic relationships of bermudagrass (Wang et al., 2011), assistance for linkage map construction and gene tagging in Brassica (Li and Quiros, 2001), and is useful in determining optimal breeding strategies for pea (Espósito et al., 2007). Budak et al. (2004) used SRAP markers to evaluate the genetic diversity of buffalograss (Buchloe dactyloides), and the results showed that genotypes with potential for turfgrass improvement could be distinguished readily based on SRAP. PCR-based technologies, including SRAP, are effective tools for estimating genetic diversity. In the present study, 30 pairs of SRAP primer combinations were used 


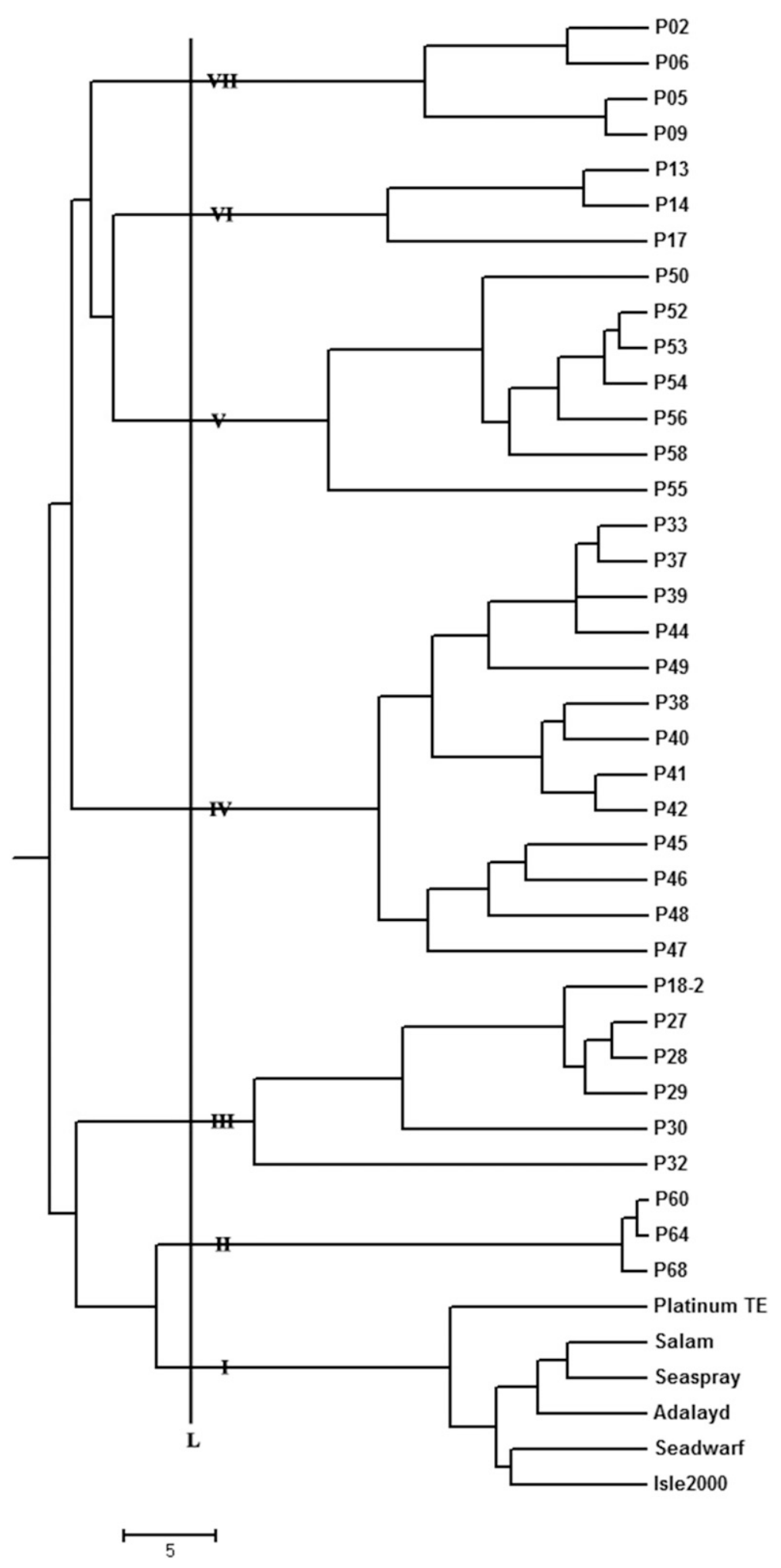

Fig. 2. An unweighted pair group method arithmetic mean dendrogram revealing genetic relationships among 42 Paspalum vaginatum accessions based on Nei's genetic distance. The $\mathrm{L}_{1}$ line indicates a cutoff point that was assigned and placed the 42 seashore paspalum accessions into seven clusters. The 5 (bar) refers to rescaled genetic distance.

to analyze the genetic diversity of 42 seashore paspalum, and a total of 374 clear bands, including 321 polymorphic bands [percentage of polymorphic loci $(\mathrm{PPL})=85.83 \%$ ], were generated. These results also demonstrated that SRAP-PCR technology is an effective method for identifying polymorphisms to estimate the genetic diversity of $P$. vaginatum.

The genetic diversity of seashore paspalum has been studied using various molecular markers. Liu et al. (1994) analyzed the genetic relationships and variation of $P$. vaginatum by RAPD markers. He reported an average of six fragments per primer and a total of 195 reproducible RAPD fragments, of which 169 fragments (PPL $=87 \%$ ) were polymorphic. Chen et al. (2009) assessed the genetic diversity of 10 seashore paspalum cultivars, 14 bermudagrass cultivars, and 24 zoysiagrass (Zoysia japonica) cultivars and elite lines, and the results demonstrated that the level of polymorphism in seashore paspalum is the lowest (PPL $=20 \%$ ). In the present study, the genetic diversity of 42 seashore paspalum germplasm resources, including 36 Chinese resources and six U.S. cultivars, was analyzed using 30 pairs of SRAP markers. The results showed wide genetic variation among the different tested materials, and the percentage of polymorphic fragments was $87 \%$. However, the polymorphism among U.S. cultivars was less, and greater genetic similarity coefficients were detected among the six U.S. cultivars (range, 0.7781-0.9171). These results are consistent with those of Chen et al. (2009) and Liu et al. (1994).

Molecular marker cluster analysis by UPGMA showed that $42 P$. vaginatum were grouped into seven major clusters. The results were different from those obtained from the dendrograms generated based on morphological traits. The cluster results showed that most materials from the same areas could form a group based on molecular markers, but not based on morphological traits. For example, all the introduced cultivars clustered together based on SRAP markers, and the genetic distance is far from that of the Chinese resources. However, the results of clustering based on morphological characteristics showed that the U.S. cultivar Adalayd clustered together with the four Chinese resources and was referred to as the fine-leaf texture and high-density ecotype. The other five U.S. cultivars were referred to as the dwarf and high-density ecotype according to morphological traits. The Chinese resources P60, P64, and P68, which were collected from different areas in Hainan, clustered together based on the SRAP markers. However, these cultivars belong to different groups and ecotypes based on the morphological clustering. García et al. (2007) also reported that morphological markers do not discriminate individuals by their geographic origin. Certain accessions always have similar morphological characteristics when grown in the same envi- 
ronment; however, their genetic basis will not necessarily be the same. The accessions with a similar genetic basis clustered together based on the molecular markers; however, their morphological traits may be different because of the influence of the environment. In the present study, two methods were used to analyze the diversity and genetic relationship of Chinese seashore paspalum resources and six U.S. cultivars. The two methods complement each other well. We first analyzed the genetic diversity of Chinese seashore paspalum, and these results provide useful information for further studies, breeding, and application of these resources.

\section{Literature Cited}

Brosnan, J.T. and J. Deputy. 2008. Seashore paspalum. Univ. Hawaii Manoa, Coop. Ext. Serv. TM-1.

Budak, H., R.C. Shearman, I. Parmaksiz, R.E. Gaussoin, T.P. Riordan, and I. Dweikat. 2004. Molecular characterization of buffalograss germplasm using sequence-related amplified polymorphism markers. Theor. Appl. Genet. 108:328-334.

Chakravarthi, B.K. and R. Naravaneni. 2006. SSR marker based DNA fingerprinting and diversity study in rice (Oryza sativa. L). Afr. J. Biotechnol. 5:684-688.

Chang, P.P., X.X. Zhong, J.Z. Wu, Y.X. Shen, and Z.W. Liu. 2011. Specificity of leaf epidermis micromorphology in new material of seashore paspalum. Jiangsu J. Agr. Sci. 27:1335-1338.

Chen, Z.B., M.L. Wang, C. Waltz, and P. Raymer. 2009. Genetic diversity of warm-season turfgrass: Seashore paspalum, bermudagrass, and zoysiagrass revealed by AFLPs. Floricult. Ornam. Biotechnol. 3:20-24.

Duncan, R.R. 1994. Seashore paspalum may be grass for the year 2000. Southern Turf Mgt. 5(1):31-32.

Duncan, R.R. 1999. Environmental compatibility of seashore paspalum (saltwater couch) for golf courses and other recreations uses: I. Breeding and genetics. Intl. Turfgrass Soc. Res. J. 8:1208-1215.

Duncan, R.R. and R.N. Carrow. 2000. Seashore paspalum: The environmental turfgrass. Ann Arbor Press, Chelsea, MI.

Echarte, A.M. and A.M. Clausen. 1993. Morphological affinities between Paspalum distichum sensu lato and P. vaginatum (Poaceae). Bol. Soc. Argent. Bot. 29:143-152.

Espinoza, F. and C.L. Quarín. 1997. Cytoembryology of Paspalum chaseanum and sexual diploid biotypes of two apomictic Paspalum species. Austral. J. Bot. 45:871-877.

Espósito, M.A., E.A. Martin, V.P. Cravero, and E. Cointry. 2007. Characterization of pea accessions by SRAP's markers. Scientia Hort. 113:329-335.

Eudy, D., B.A. Bahri, M.L. Harrison, P. Raymer, and K.M. Devos. 2017. Ploidy level and genetic diversity in the genus Paspalum, group Disticha. Crop Sci. 57:3319-3332.

Ferriol, M., B. Pico, and F. Nuez. 2003. Genetic diversity of a germplasm collection of Cucurbita pepo using SRAP and AFLP markers. Theor. Appl. Genet. 107:271-282.

García, M.V., M.J. Arturi, and O.E. Ansín. 2002. Phenotypic and genetic variability in wild populations of dallis grass (Paspalum dilatatum Poir.). Agric. Téc. 62:237-244.

García, M.V., P.A. Balatti, and M.J. Arturi. 2007. Genetic variability in natural populations of Paspalum dilatatum Poir. analyzed by means of morphological traits and molecular markers. Genet. Resources Crop Evol. 54:935-946.

Haji, R.F.A., M. Bhargava, B.A. Akhoon, A. Kumar, N.B. Brindavanam, and V. Verma. 2014. Correlation and functional differentiation between different markers to study the genetic diversity analysis in medicinally important plant Plumbago zeylanica. Ind. Crops Prod. 55:75-82.

Harivandi, M.A., W. Davis, V.A. Gibeault, M. Henry, J. Van Dam, and L. Wu. 1984. Selecting the best turfgrass. Calif. Turfgrass Cult. 34(4):17-20.
Hojsgaard, D., A.I. Honfi, G. Rua, and J. Davina. 2009. Chromosome numbers and ploidy levels of Paspalum species from sub-tropical South America (Poaceae). Genet. Resources Crop Evol. 56:533-545. Huang, B., R.R. Duncan, and R.N. Carrow. 1997. Drought resistance mechanisms of seven warm-season grasses under surface soil drying: I. Shoot response. Crop Sci. 37:1863-1869.

Jarret, R.L., Z.W. Liu, and R.W. Webster. 1998. Genetic diversity among Paspalum spp. as determined by RFLPs. Euphytica 104:119125.

Jewell, M.C., Y. Zhou, D.S. Loch, I.D. Godwin, and C.J. Lambrides. 2012. Maximizing genetic, morphological, and geographic diversity in a core collection of Australian bermudagrass. Crop Sci. 52:879889.

Jiang, Y., R.R. Duncan, and R.N. Carrow. 2004. Assessment of low light tolerance of seashore paspalum and bermudagrass. Crop Sci. 44:587-594.

Khadivi-Khub, A., H. Salehi-Arjmand, and J. Hadian. 2014. Morphological and phytochemical variation of Satureja bachitarica populations from Iran. Ind. Crops Prod. 54:257-265.

Kumar, S., K. Tamura, and M. Nei. 2004. MEGA3: Integrated software for molecular evolutionary genetics analysis and sequence alignment. Brief. Bioinform. 5:150-163.

Li, G. and C.F. Quiros. 2001. Sequence-related amplified polymorphism (SRAP), a new marker system based on a simple PCR reaction: Its application to mapping and gene tagging in Brassica. Theor. Appl. Genet. 103:455-461.

Liu, Z.W., R.L. Jarret, R.R. Duncan, and S. Kresovich. 1994. Genetic relationships and variation among ecotypes of seashore paspalum(Paspalum vaginatum)determined by random amplified polymorphic DNA markers. Genome 37:1011-1017.

Liu, Z.W., R.L. Jarret, S. Kresovich, and R.R. Duncan. 1995. Characterization and analysis of simple sequence repeat (SSR) loci in seashore paspalum (Paspalum vaginatum Swartz). Theor. Appl. Genet. 91:47-52.

Liu, Y., Y. Wang, J.J. Ma, J.A. Shi, Z.Y. Wang, J.X. Liu, and H.L. Guo. 2016. Optimization of SRAP-PCR system in Paspalum vaginatum and primers screening. Acta Agrestia Sinica 24:10801086.

Luo, X.B., Z.X. Xiang, and L.Q. Hu. 2013. Turf quality of seashore paspalum line 09-1. Crop Res. 27:57-61.

Mishra, M.K., N. Suresh, A.M. Bhat, N. Suryaprakash, S.S. Kumar, A. Kumar, and Jayarama. 2011. Genetic molecular analysis of Coffea arabica (Rubiaceae) hybrids using SRAP markers. Rev. Biol. Trop. 59:607-617.

Trenholm, L.E. and J.B. Unruh. 2002. Seashore paspalum for Florida lawns. Dept. Environ. Hort., Florida Coop. Ext. Serv., Inst. Food Agricultural Sci., Univ. Florida, CRR 1244.

Wang, Z.Y., L. Liao, X.J. Yuan, A.G. Guo, and J.X. Liu. 2011. Genetic relationships of bermudagrass (Cynodon dactylon var. dactylon) from different countries revealed by sequence-related amplified polymorphism (SRAP) analysis. Afr. J. Biotechnol. 10:1710617115.

Xie, X.M. 2004. Genetic diversity of seashore paspalum (Paspalum vaginatum) based on RAPD molecular markers. J. South China Agr. Univ. 25:64-67.

Yang, P., X.J. Liu, X.C. Liu, W.Y. Yang, and Z.Y. Feng. 2010. Diversity analysis of the developed qingke (hulless barley) cultivars representing different growing regions of the Qinghai-Tibet Plateau in China using sequence related amplified polymorphism (SRAP) markers. Afr. J. Biotechnol. 9:8530-8538.

Yeh, F.C., R.C. Yang, T.B.J. Boyle, Z.H. Ye, and J.X. Mao. 1997. POPGENE, the user-friendly shareware for population genetic analysis. Molecular Biology and Biotechnology Center, University of Alberta, Edmonton, AB, Canada.

Zheng, Y.Q., Y. Guo, J. Liu, Y.Z. Liu, and L. Zhang. 2015. Study on the phenotypic diversity of Cynodon dactylon collected from Luoyang city. Northern Hort. 39(1):72-75. 


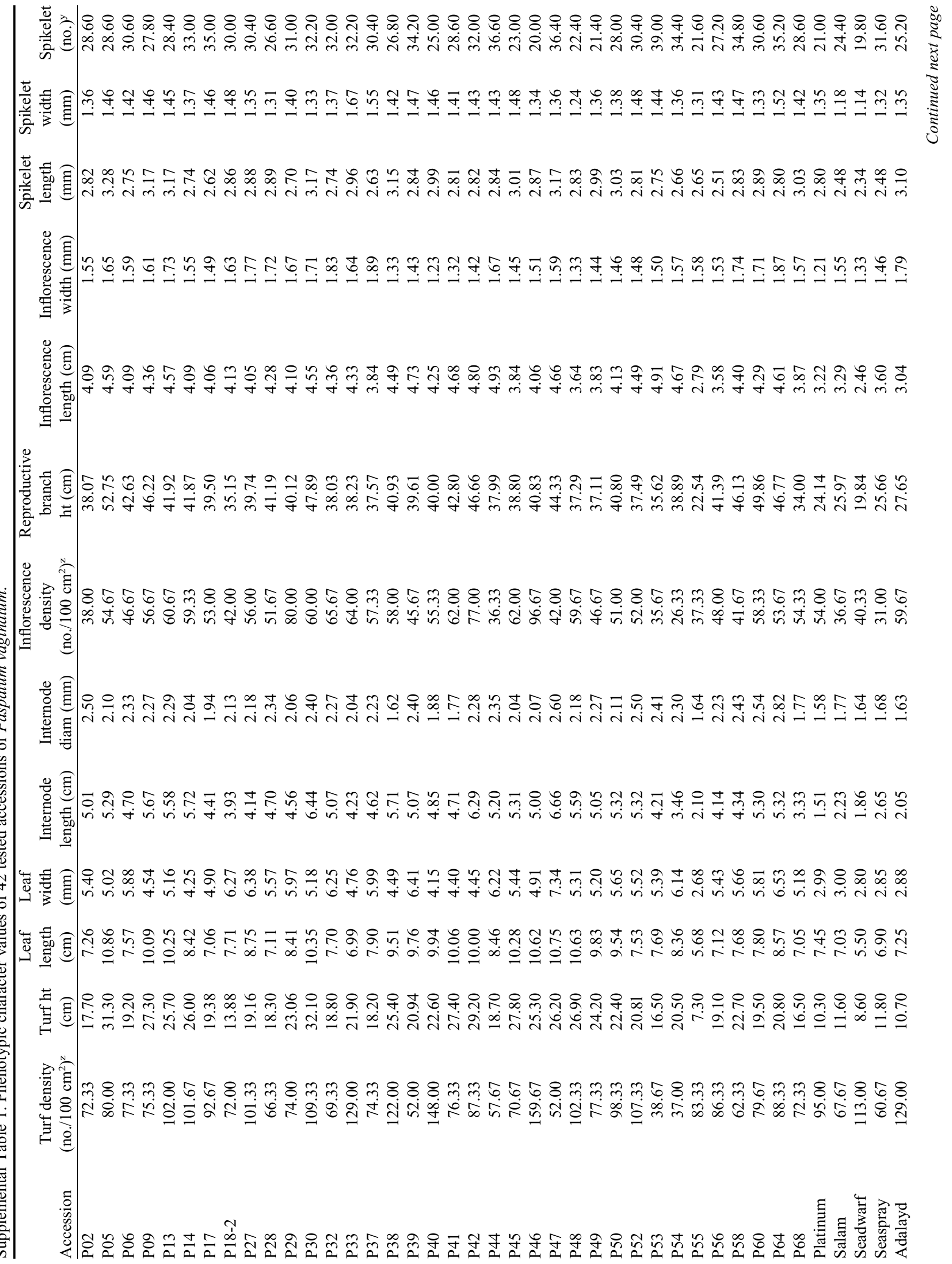




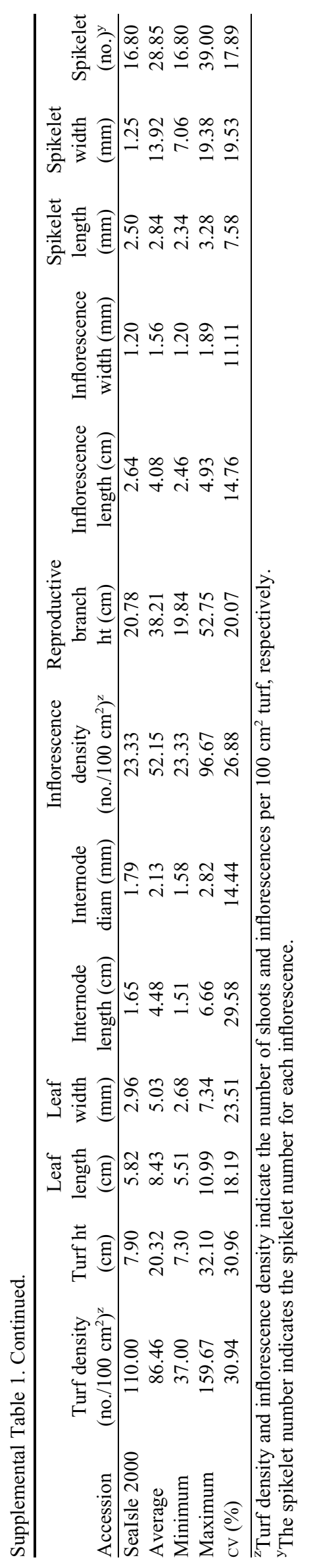

